\title{
Phlebotomine sandflies (Diptera: Psychodidae) collected in Mukusu, Machakos District, Kenya and their nocturnal flight activity
}

\author{
Eiko Kan, ${ }^{1, *, \dagger}$ Christopher O. AnJILI, ${ }^{2}$ Rajindar K. SAInI, ${ }^{1}$ Toshitaka HIDAKA ${ }^{3, \ddagger}$ and \\ John I. GITHURE ${ }^{2}$ \\ ${ }^{1}$ Behavioural Biology Department, The International Centre of Insect Physiology and Ecology (ICIPE); P. O. Box 30772, Nairobi, \\ Kenya \\ ${ }^{2}$ Biomedical Sciences Research Centre, Kenya Medical Research Institute (KEMRI); P. O. Box 54840, Nairobi, Kenya \\ ${ }^{3}$ The University of Shiga Prefecture; Hikone, Shiga 522-8533, Japan
}

(Received 10 October 2003; Accepted 16 July 2004)

\begin{abstract}
This is the first report on the nocturnal flight activity of the phlebotomine sandflies in the field by trap collection in Mukusu, Masinga, the kala-azar (visceral leishmaniasis in humans) area in Kenya. A total of 514 sandflies were collected with three different types of traps (sticky traps, CDC light traps and a goat-baited trap), and seven species of two genera (Sergentomyia and Phlebotomus) were identified. The number of Sergentomyia bedfordi Newstead individuals captured was the largest among these seven species. This suggests that $S$. bedfordi is the most common among the seven species in Mukusu. The result of the sticky trap collection suggests that the wild sandflies are nocturnally active, with the highest flight activity level soon after sunset, at least for $S$. bedfordi. The proportion of females collected was extremely high both in the sticky and light trap collections. It is suggested that this is due to site tenaciousness or weaker dispersal urge of males. Phlebotomus martini Parrot, S. bedfordi and S. schwetzi Adler, Theodor and Parrot were collected in the goat-baited trap. Examination of the physiological conditions of a total of 495 females collected showed that almost all females were unfed and nulliparous. This suggests that younger females show stronger nocturnal flight activity.
\end{abstract}

Key words: Phlebotomine sandflies; traps; flight activity; kala-azar; Kenya

\section{INTRODUCTION}

The subfamily Phlebotominae has a wide distribution throughout the world, mainly in the tropics and subtropics (Adler and Theodor, 1957). Phlebotomine sandflies are small, blood-sucking dipteran insects. Only female sandflies feed on blood of various vertebrate animals such as reptiles and mammals including man, and use the nutrients to develop eggs (Lane, 1987). Most species of this group are gonotrophically concordant, taking one blood meal for each batch of eggs matured (Lane, 1987).

The phlebotomine sandflies are widely known as vectors of several human leishmaniases (Lane, 1987). The Phlebotominae contains about 600 species and subspecies, and about 70 among these are proven or suspected vectors of a definite type of leishmaniasis (WHO, 1984).

The phlebotomine sandflies are usually crepuscular-nocturnal in their activity (Lewis, 1971). When they are active, they fly to disperse, to feed, to find mates, to search for oviposition sites, and so on.

In Kenya, both visceral leishmaniasis (kalaazar) and cutaneous leishmaniasis are endemic (Mutinga, 1985; Muigai et al., 1987). Therefore, the phlebotomine sandflies in Kenya have been studied by many authors mainly from the viewpoint of epidemiology. Fragmentary reports on the biology of Kenyan sandflies have been published by several authors such as Heisch et al. (1956),

\footnotetext{
* To whom correspondence should be addressed at: E-mail: eikokan@ta.laox.net

$\dagger$ Present address: Department of Medical Zoology, School of Medicine, Mie University, Tsu, Mie 514-0001, Japan

¥ Present address: Research Institute for Humanity and Nature, Kyoto 602-0878, Japan DOI: $10.1303 /$ aez.2004.651
} 
Minter (1963a, 1964), Mutinga and Kamau (1986), Mutinga et al. (1986a,b) and Basimike et al. (1992a,b): these authors have reported on the distribution, seasonal change in population, breeding sites, host preference, biting-cycle, and so on, of several sandfly species, mainly in Kitui and Baringo Districts, which are major epidemic foci of kala-azar. However, except for these studies, little is known about the biology of the wild sandflies in Kenya.

In this study, collections by three different types of traps were done to clarify the characteristics of nocturnal flight activity and species composition of sandflies which inhabit Mukusu, Masinga, Machakos District, another major epidemic focus of kala-azar in Kenya (Mutinga, 1985). Usually, there are two rainy seasons in a year (March to May and October to December). The sandflies in the Masinga area occur throughout the year with, usually, two peak periods (April to June and November to February; Anjili, pers. comm.). It is generally known that the sandflies in the study site are nocturnal, resting mainly in termite mounds during the day.

\section{MATERIALS AND METHODS}

Study site. The field study was undertaken at an open area in Mukusu $\left(0^{\circ} 55^{\prime} \mathrm{S} ; 37^{\circ} 39^{\prime} \mathrm{E}\right)$, Masinga, Machakos District, Kenya on three nights from 23 to 26 January 1996. Mukusu is located about $100 \mathrm{~km}$ northeast of Nairobi. The study site was characterized by scattered termite mounds in an Acacia savanna, and there was no human dwelling. To capture sandflies in the field, three different types of traps (sticky traps, light traps and a goatbaited trap) were used. These three different types of traps were arranged in a nearly straight line, and the sticky traps were located at the middle point of the line. Distance between the sticky traps and the light traps and that between the sticky traps and the goat-baited trap was about $80 \mathrm{~m}$. Collections of sandflies with the three different types of traps were made as follows.

Sticky trap collection. This trap was a sheet of plain copying paper $(210 \times 297 \mathrm{~mm})$ coated with castor oil. This type of trap is available to collect sandflies in a termite mound when they fly out of its ventilation shaft and, so far, has been used by many authors in the field. Collections were done on two successive nights of 23 and 24 January, each from 18:00 to 6:00 the next morning. Two hours before sunset of each night, one trap (i.e. one sheet of oiled paper) was placed in each one of the four fixed ventilation shafts of a termite mound built by Macrotermes sp. 1. Each trap (each sheet of oiled paper) was replaced hourly during the $12 \mathrm{~h}$-night period to elucidate the temporal activity pattern of sandfly nocturnal flight. Therefore, a total of 96 traps (96 sheets of oiled paper) were used for this two-night collection.

The sandflies adhering to the oiled papers were collected with a fine paintbrush. Species, sex and female physiological condition of the collected sandflies were examined after the preparations described below. This examination was also made for other sandflies collected with the light traps and the goat-baited trap.

Light trap collection. The light trap collection was made on two successive nights of 23 and 24 January, each from 18:00 to 6:00 the next morning. Two standard CDC light traps (Sudia and Chamberlain, 1962) were set up about $2 \mathrm{~h}$ before sunset. They were hung at $1.5 \mathrm{~m}$ above the ground, separately from two different twigs of a thorn tree ( $\mathrm{Aca}$ cia sp.) located near a termite mound built by Macrotermes sp. 2. The attracted sandflies fell into the mesh-collection bag of the trap. The collection bag of each trap was changed at 24:00. The sandflies captured in the bag were collected with an aspirator at 24:00 and at 6:00 the following morning.

Goat-baited-trap collection. The goat-baitedtrap collection was made on the third night from 19:00 of 25 January to 1:00 of 26 January. Although it was not clear whether the goat (Capra hircus Linnaeus) is the usual host for certain species of Kenyan sandflies in nature, the goat was selected as the bait animal because this type of trap has been used by several authors (e.g. Mutinga et al., 1986b) to collect wild sandflies in Kenya and the goat is a commonly found domestic animal in Mukusu, usually kept in enclosures very close to human dwellings. A family of four domestic goats (a male and female adult and two kids) were kept together in a white tent $(1.5 \times 1.5 \times 1.5 \mathrm{~m})$ set at a place near a termite mound built by Macrotermes sp. 3. This tent of nylon netting with a mesh of 11 filaments per $\mathrm{cm}$ (too small for the sandflies to pass through but allowing air flow) had an opening 


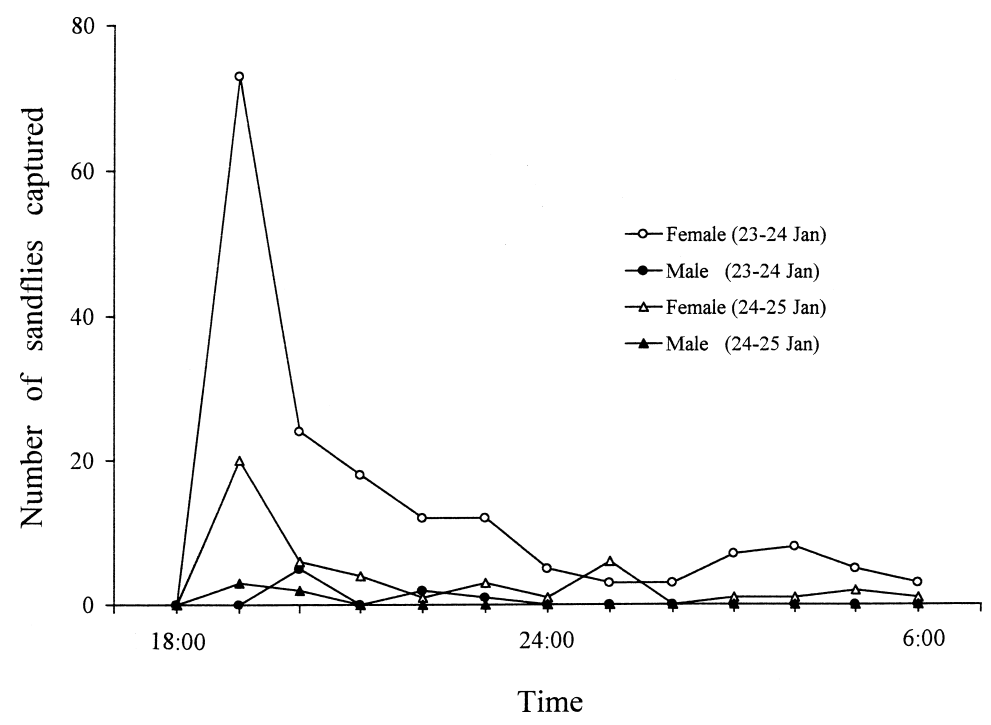

Fig. 1. Temporal changes in the number of each sex of sandflies captured per sticky trap set (four sheets of oiled paper) on the two nights of 24 and 25 January 1996 in Mukusu, Masinga, Machakos District, Kenya, each, from 18:00 to 6:00 the following morning.

$(0.85 \times 1 \mathrm{~m})$ at one side through which sandflies could enter to feed on the goats. This goat-baited trap was settled about $2 \mathrm{~h}$ before sunset. The sandflies in the trap were collected hourly with an aspirator.

Preparations for microscopy. Sandfly specimens from each collection were cleared and mounted for species identifications. The sandflies adhering to the sticky traps were dead at the time of collection. The sandflies captured with the light traps and the goat-baited trap were alive at the time of collection. They were killed by ether and transferred to Nesbitt's solution (see Minter, 1963b) for clearing, being left for about $48 \mathrm{~h}$. The cleared specimens were rinsed in $2 \%$ solution of detergent in normal insect saline.

The rinsed specimens were separated by sex under a microscope. After being sexed, male sandflies were mounted in Puri's chloral-gum mountant for species identification, according to the method used by Minter (1963b). For female sandflies, dissection was made before mounting. They were dissected in normal insect saline under a microscope to examine their physiological condition: unfed (no blood in the midgut), blood-fed or gravid. Furthermore, through another examination, the females were divided into parous and nulliparous, depending on the presence or absence of granules in the accessory glands according to the criterion of Adler and Theodor (1957) and Lewis and Minter (1960): a female that had granules in the accessory glands was regarded as parous. After these examinations, the dissected females were mounted for species identification in the same way as the males.

\section{RESULTS}

\section{Sticky trap collection}

In Mukusu the time of sunset was 18:48 on both nights of 23 and 24 January 1996. The time of sunrise on the following morning was 6:40 on both days. It was clear during the two nights. On the night of 23 January, a total of 181 sandflies consisting of 173 (95.6\%) females and eight (4.4\%) males were captured. On the night of 24 January, a total of 51 sandflies consisting of $46(90.2 \%)$ females and five $(9.8 \%)$ males were captured. Temporal changes in the numbers of each sex of sandflies captured per trap set (four sheets of oiled paper) on the two nights, each from 18:00 to 6:00 the following morning are shown in Fig. 1. On the night of 23 January, the number of female individuals captured per trap set per $h$ reached a peak of 73 at 19:00, and then decreased rapidly to three at 6:00. The peak number of male individuals was five at 20:00, and no male was captured after 23:00. On the night of 24 January, the number of female individuals captured per trap set per $\mathrm{h}$ reached a peak of 20 at 19:00, and then decreased rapidly. 
Table 1. Species and sex composition of sandflies in the sticky trap collection in Mukusu, Masinga, Machakos District, Kenya on the two nights from 23 to 25 January 1996.

Temporal pattern of the capture for each sex is shown in Fig. 1.

\begin{tabular}{|c|c|c|c|c|c|c|}
\hline \multirow{3}{*}{ Species } & \multicolumn{6}{|c|}{ Number of sandflies captured ${ }^{\mathrm{a}}$} \\
\hline & \multicolumn{3}{|c|}{ 23-24 Jan. } & \multicolumn{3}{|c|}{ 24-25 Jan. } \\
\hline & Female & Male & Total & Female & Male & Total \\
\hline Phlebotomus martini & $1(25.0)$ & $3(75.0)$ & $4(100.0)$ & $0(0.0)$ & $1(100.0)$ & $1(100.0)$ \\
\hline P. rodhaini & $1(100.0)$ & $0(0.0)$ & $1(100.0)$ & - & - & - \\
\hline Sergentomyia affinis & - & - & - & $1(100.0)$ & $0(\quad 0.0)$ & $1(100.0)$ \\
\hline S. bedfordi & 169 ( 97.7) & $4(2.3)$ & $173(100.0)$ & $45(91.8)$ & $4(8.2)$ & $49(100.0)$ \\
\hline S. schwetzi & $2(66.7)$ & $1(33.3)$ & $3(100.0)$ & - & - & - \\
\hline Total & $173(95.6)$ & $8(4.4)$ & $181(100.0)$ & $46(90.2)$ & $5(9.8)$ & $51(100.0)$ \\
\hline
\end{tabular}

${ }^{a}$ Values in parentheses indicate percentages.

The males were collected only at 19:00 $(N=3)$ and 20:00 $(N=2)$, and no male was captured after 20:00.

Species composition of the sandflies in the sticky trap collection on the two nights is shown in Table 1. In the collection on the night of 23 January, four species of sandflies (Phlebotomus martini Parrot, P. rodhaini Parrot, Sergentomyia bedfordi Newstead and S. schwetzi Adler, Theodor and Parrot) were identified. The largest number of individuals captured was $173(95.6 \%)$ in S. bedfordi. The 173 S. bedfordi sandflies consisted of 169 females and four males. These 169 females were captured from 19:00 to 6:00 but all four males were captured at 20:00. The total number of individuals captured among the remaining three species (P. martini, P. rodhaini and S. schwetzi) was eight and they were captured from 20:00 to 23:00 as follows. P. martini: four individuals consisting of a single female and three males were captured. The female was captured at 21:00 and the three males were captured at 20:00, 22:00 and 23:00, respectively. P. rodhaini: only one individual, a female, was captured at 21:00. S. schwetzi: two individuals, a female and a male were captured at 20:00 and 23:00, respectively.

In the collection on the night of 24 January, three species of sandflies ( $P$. martini, $S$. affinis Theodor and $S$. bedfordi) were identified (Table 1). The largest number of individuals captured was 49 (96.1\%) in S. bedfordi. The 49 S. bedfordi sandflies consisted of 45 females and four males. S. bedfordi females $(N=45)$ were captured from 19:00 to 1:00 $(N=40)$ and from 3:00 to 6:00 $(N=5)$, and males $(N=4)$ were captured at 19:00 $(N=3)$ and 20:00 $(N=1)$. Among the other two species (P. martini and $S$. affinis), only two individuals were captured, a male $P$. martini, captured at 20:00 and, a female S. affinis, captured at 19:00.

The physiological condition of the females captured on the two nights is shown in Table 2. One hundred seventy-two $(99.4 \%)$ of the females captured on the night of 23 January $(N=173)$ were unfed and nulliparous, and only one female $S$. bedfordi was blood-fed and parous. This blood-fed and parous female was collected at 20:00. All of the females captured on the night of 24 January $(N=46)$ were unfed and nulliparous.

\section{Light trap collection}

The numbers of sandflies, that were captured with the two CDC light traps on the two nights of 23 and 24 January 1996, each from 18:00 to 6:00 the following morning, are shown in Table 3. On the night of 23 January, a total of 215 sandflies were captured and all were females. Thirty-eight $(17.7 \%)$ of these were captured in the first half of the night (18:00 to 24:00) and $177(82.3 \%)$ were captured in the second half (24:00 to 6:00). On the night of 24 January, a total of 44 sandflies consisting of $43(97.7 \%)$ females and one $(2.3 \%)$ male were captured. Nine $(20.5 \%)$ of these were captured in the first half and 35 (79.5\%) were captured in the second half. 
Table 2. Physiological condition of female sandflies in the sticky trap collection in Mukusu, Masinga,

Machakos District, Kenya on the two nights from 23 to 25 January 1996

\begin{tabular}{|c|c|c|c|c|c|c|c|c|c|c|c|}
\hline \multirow{4}{*}{ Species } & \multicolumn{11}{|c|}{ Physiological condition and number of female sandflies captured } \\
\hline & \multicolumn{6}{|c|}{ 23-24 Jan. } & \multicolumn{5}{|c|}{ 24-25 Jan. } \\
\hline & \multicolumn{2}{|c|}{ Blood-fed } & \multicolumn{2}{|c|}{ Unfed } & \multirow{2}{*}{ Gravid } & \multirow{2}{*}{ Total } & \multirow{2}{*}{ Blood-fed } & \multicolumn{2}{|c|}{ Unfed } & \multirow{2}{*}{ Gravid } & \multirow{2}{*}{ Total } \\
\hline & Parous & Nulliparous & Parous & Nulliparous & & & & Parous & Nulliparous & & \\
\hline Phlebotomus martini & 0 & 0 & 0 & 1 & 0 & 1 & - & - & - & - & - \\
\hline P. rodhaini & 0 & 0 & 0 & 1 & 0 & 1 & - & - & - & - & - \\
\hline Sergentomyia affinis & - & - & - & - & - & - & 0 & 0 & 1 & 0 & 1 \\
\hline S. bedfordi & 1 & 0 & 0 & 168 & 0 & 169 & 0 & 0 & 45 & 0 & 45 \\
\hline S. schwetzi & 0 & 0 & 0 & 2 & 0 & 2 & - & - & - & - & - \\
\hline Total & 1 & 0 & 0 & 172 & 0 & 173 & 0 & 0 & 46 & 0 & 46 \\
\hline
\end{tabular}

Table 3. Number of sandflies in the light trap collection in Mukusu, Masinga, Machakos District, Kenya on the two nights from 23 to 25 January 1996

\begin{tabular}{|c|c|c|c|c|c|c|}
\hline \multirow{3}{*}{ Species and sex } & \multicolumn{6}{|c|}{ Number of sandflies captured ${ }^{a}$} \\
\hline & \multicolumn{3}{|c|}{ 23-24 Jan. } & \multicolumn{3}{|c|}{ 24-25 Jan. } \\
\hline & $18: 00-24: 00$ & $24: 00-6.00$ & Total & $18: 00-24: 00$ & $24: 00-6: 00$ & Total \\
\hline \multicolumn{7}{|l|}{ Female } \\
\hline Phlebotomus martini & 2 & 1 & 3 & 0 & 0 & 0 \\
\hline Sergentomyia africanus & - & - & - & 0 & 1 & 1 \\
\hline S. antennatus & - & - & - & 0 & 1 & 1 \\
\hline S. bedfordi & 33 & 174 & 207 & 8 & 30 & 38 \\
\hline S. schwetzi & 3 & 2 & 5 & 0 & 3 & 3 \\
\hline \multicolumn{7}{|l|}{ Male } \\
\hline P. martini & 0 & 0 & 0 & 1 & 0 & 1 \\
\hline S. africanus & - & - & - & 0 & 0 & 0 \\
\hline S. antennatus & - & - & - & 0 & 0 & 0 \\
\hline S. bedfordi & 0 & 0 & 0 & 0 & 0 & 0 \\
\hline S. schwetzi & 0 & 0 & 0 & 0 & 0 & 0 \\
\hline Total & $38(17.7)$ & $177(82.3)$ & $215(100.0)$ & $9(20.5)$ & $35(79.5)$ & $44(100.0)$ \\
\hline
\end{tabular}

${ }^{a}$ Values in parentheses indicate percentages.

Species composition of the sandflies captured on the two nights is shown in Table 4. In the collection on the night of 23 January, three species of sandflies (P. martini, S. bedfordi and S. schwetzi) were identified. The largest number of individuals captured was $207(96.3 \%)$ in S. bedfordi. As shown in Table 3, in S. bedfordi, 33 (15.9\%) of the 207 females were captured in the first half of the night and $174(84.1 \%)$ were captured in the second half. Although only eight females of the other two species (P. martini and S. schwetzi) were captured, they were captured both in the first half and in the second half (Tables 3 and 4).

In the collection on the night of 24 January, five species of sandflies (P. martini, S. africanus Newstead, $S$. antennatus Newstead, $S$. bedfordi and $S$. schwetzi) were identified (Table 4). Sandflies of the four Sergentomyia species (S. africanus, S. antennatus, S. bedfordi and S. schwetzi) were all females $(N=43)$. Only one $P$. martini male was 
Table 4. Species and sex composition of sandflies in the light trap collection in Mukusu, Masinga, Machakos District, Kenya on the two nights from 23 to 25 January 1996

\begin{tabular}{|c|c|c|c|c|c|c|}
\hline \multirow{3}{*}{ Species } & \multicolumn{6}{|c|}{ Number of sandflies captured ${ }^{a}$} \\
\hline & \multicolumn{3}{|c|}{ 23-24 Jan. } & \multicolumn{3}{|c|}{ 24-25 Jan. } \\
\hline & Female & Male & Total & Female & Male & Total \\
\hline Phlebotomus martini & $3(100.0)$ & $0(\quad 0.0)$ & $3(100.0)$ & $0(0.0)$ & $1(100.0)$ & $1(100.0)$ \\
\hline Sergentomyia africanus & - & - & - & $1(100.0)$ & $0(0.0)$ & $1(100.0)$ \\
\hline S. antennatus & - & - & - & $1(100.0)$ & $0(0.0)$ & $1(100.0)$ \\
\hline S. bedfordi & $207(100.0)$ & $0(0.0)$ & $207(100.0)$ & $38(100.0)$ & $0(0.0)$ & $38(100.0)$ \\
\hline S. schwetzi & $5(100.0)$ & $0(\quad 0.0)$ & $5(100.0)$ & $3(100.0)$ & $0(0.0)$ & $3(100.0)$ \\
\hline Total & $215(100.0)$ & $0(0.0)$ & $215(100.0)$ & $43(97.7)$ & $1(2.3)$ & $44(100.0)$ \\
\hline
\end{tabular}

${ }^{\text {a }}$ Values in parentheses indicate percentages.

Table 5. Physiological condition of female sandflies in the light trap collection in Mukusu, Masinga, Machakos District, Kenya on the two nights from 23 to 25 January 1996

\begin{tabular}{|c|c|c|c|c|c|c|c|c|c|c|}
\hline \multirow{5}{*}{ Species } & \multicolumn{10}{|c|}{ Physiological condition and number of female sandflies captured } \\
\hline & \multicolumn{5}{|c|}{ 23-24 Jan. } & \multicolumn{5}{|c|}{ 24-25 Jan. } \\
\hline & \multirow{3}{*}{ Blood-fed } & \multicolumn{2}{|c|}{ Unfed } & \multirow{3}{*}{ Gravid } & \multirow{3}{*}{ Total } & \multirow{3}{*}{ Blood-fed } & \multicolumn{2}{|c|}{ Unfed } & \multirow{3}{*}{ Gravid } & \multirow{3}{*}{ Total } \\
\hline & & & & & & & & & & \\
\hline & & Parous & Nulliparous & & & & Parous & Nulliparous & & \\
\hline Phlebotomus martini & 0 & 0 & 3 & 0 & 3 & - & - & - & - & - \\
\hline Sergentomyia africanus & - & - & - & - & - & 0 & 0 & 1 & 0 & 1 \\
\hline S. antennatus & - & - & - & - & - & 0 & 0 & 1 & 0 & 1 \\
\hline S. bedfordi & 0 & 1 & 206 & 0 & 207 & 0 & 1 & 37 & 0 & 38 \\
\hline S. schwetzi & 0 & 0 & 5 & 0 & 5 & 0 & 0 & 3 & 0 & 3 \\
\hline Total & 0 & 1 & 214 & 0 & 215 & 0 & 1 & 42 & 0 & 43 \\
\hline
\end{tabular}

captured. The largest number of individuals captured was $38(86.3 \%)$ in $S$. bedfordi. As shown in Table 3, eight $(21.1 \%)$ of the $38 \mathrm{~S}$. bedfordi females were captured in the first half and 30 $(78.9 \%)$ were captured in the second half. Of the three other Sergentomyia species ( $S$. africanus, $S$. antennatus and $S$. schwetzi), all of the females $(N=5)$ were captured in the second half. Only one $P$. martini male was captured in the first half (Table 3).

Physiological condition of the females captured on the two nights is shown in Table 5. All of the females captured on the night of 23 January $(N=215)$ were unfed. Two hundred fourteen (99.5\%) of them were nulliparous and only one female $S$. bedfordi was parous. This parous female was captured in the second half of the night. All of the females captured on the night of 24 January $(N=43)$ were unfed. Forty-two $(97.7 \%)$ of them were nulliparous and only one female $S$. bedfordi was parous. This parous female was captured in the second half.

\section{Goat-baited-trap collection}

Sunset on the night of 25 January 1996 was at 18:48 and it was a clear night. A total of 23 sandflies consisting of $18(78.3 \%)$ females and five (21.7\%) males were captured. Species composition of the sandflies captured with the goat-baited trap is shown in Table 6. Three species of sandflies (P. martini, S. bedfordi and S. schwetzi) were identified. The largest number of individuals captured 
Table 6. Species and sex composition of sandflies in the goat-baited-trap collection in Mukusu, Masinga, Machakos

District, Kenya on the night from 25 to 26 January 1996. Temporal pattern of the capture for each species and sex is shown in Fig. 2.

\begin{tabular}{lllr}
\hline \multirow{2}{*}{ Species } & \multicolumn{3}{c}{ Number of sandflies captured ${ }^{\mathrm{a}}$} \\
\cline { 2 - 4 } & Female & Male & Total \\
\hline Phlebotomus martini & $7(58.3)$ & $5(41.7)$ & $12(100.0)$ \\
Sergentomyia bedfordi & $8(100.0)$ & $0(0.0)$ & $8(100.0)$ \\
S. schwetzi & $3(100.0)$ & $0(0.0)$ & $3(100.0)$ \\
\hline \multicolumn{1}{c}{ Total } & $18(78.3)$ & $5(21.7)$ & $23(100.0)$
\end{tabular}

${ }^{\text {a }}$ Values in parentheses indicate percentages.

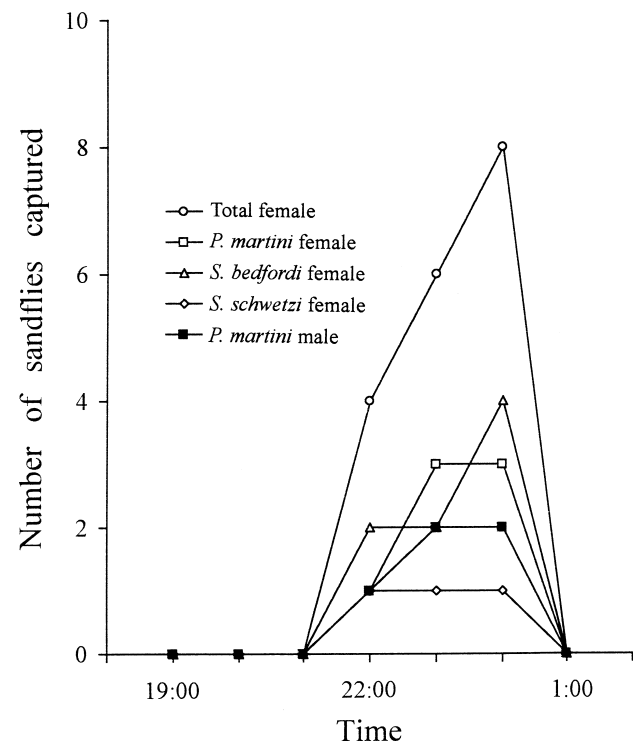

Fig. 2. Temporal changes in the number of each species and sex of sandflies captured with a single goat-baited trap from 19:00 of 25 January to 1:00 of 26 January 1996 in Mukusu, Masinga, Machakos District, Kenya. Females of three species of sandflies ( $P$. martini, $S$. bedfordi and $S$. schwetzi) and males of $P$. martini were captured. For details, see text.

was $12(52.2 \%)$ in $P$. martini. Seven (58.3\%) P. martini females and five $(41.7 \%)$ males were captured. Among the other two species (S. bedfordi and $S$. schwetzi), 11 sandflies were captured and they were all females.

Temporal change in the number of each species and sex of sandflies captured with the goat-baited trap from 19:00 of 25 January to 1:00 of 26 January is shown in Fig. 2. The sandflies of each three species were captured from 22:00 to 24:00. The peak number of $P$. martini females captured per $\mathrm{h}$ was three at 23:00 and 24:00. The peak number for $S$. bedfordi females was four at 24:00. In $S$. schwetzi, one female each was captured at 22:00, 23:00 and 24:00. On the other hand, for the males of $P$. martini, the peak number of individuals captured was only two at 23:00 and 24:00.

Among the three species, all of the females captured $(N=18)$ were unfed and nulliparous and their actual blood feeding was not observed. Furthermore, both female $(N=7)$ and male $(N=5)$ $P$. martini were captured but no copulating couple was found in the trap.

\section{DISCUSSION}

In the present study, a total of 514 phlebotomine sandflies were captured with the three different types of traps, and a total of seven species belonging to the two genera (Phlebotomus and Sergentomyia) were identified. These were P. martini, P. rodhaini, S. affinis, S. africanus, S. antennatus, $S$. bedfordi and $S$. schwetzi. Among these seven sandfly species, only P. martini is a proven vector of kala-azar in Kenya (Wijers and Minter, 1962; Mutinga and Ngoka, 1978; Perkins et al., 1988). For $S$. bedfordi, the number of individuals captured was 475 (92.4\%), the largest among the seven species, and sandflies of this species were captured with all three types of traps (Tables 1, 4 and 6). These results suggest that $S$. bedfordi is the most common among the seven sandfly species in this research season in Mukusu, although Sergentomyia is not known as a vector of human leishmaniasis.

In the present sticky trap collection, five species of sandflies ( $P$. martini, $P$. rodhaini, $S$. affinis, $S$. bedfordi and $S$. schwetzi) were captured (Table 1). This showed that the termite mound was the resting site for these five species during the day in Mukusu. Several authors (e.g. Mutinga et al., 1986b; Basimike et al., 1992b) found the termite mound to be one of the major resting sites for many sandfly species in Kenya including these five species. The present result confirmed this finding.

A few reports on the nocturnal flight activity of sandflies in nature have been published by several authors such as el Said et al. (1986). These authors studied the nocturnal flight activity of $P$. papatasi (Scopoli) and P. langeroni Nitzulescu in Egypt using the sticky traps, and determined that both 
species were nocturnally active from sunset to sunrise, with the highest activity level after midnight. The result of the present sticky trap collection (see Fig. 1) showed the nocturnal flight activity pattern of the five sandfly species ( $P$. martini, P. rodhaini, S. affinis, S. bedfordi and $S$. schwetzi) as a whole in Mukusu. In this trap collection, more than $95 \%$ of the sandflies captured on both nights were $S$. bedfordi (Table 1). Therefore, this result (see Fig. 1) showed essentially the flight activity pattern of $S$. bedfordi. In contrast to the nocturnal flight activity of $P$. papatasi and $P$. langeroni (el Said et al., 1986), the result of the present sticky trap collection suggests that the five species of sandflies captured in Mukusu (P. martini, P. rodhaini, $S$. affinis, $S$. bedfordi and $S$. schwetzi) are also nocturnally active but have the highest flight activity level soon after sunset, at least for $S$. bedfordi.

The nocturnal flight activity of the sandflies in Mukusu was also investigated in the present light trap collection. In this trap collection, more than $85 \%$ of the sandflies captured on both nights were $S$. bedfordi (Table 4). Therefore, the result of the present light trap collection (see Table 3) showed essentially a pattern of nocturnal flight activity in $S$. bedfordi. This result suggests that the nocturnal flight activity of $S$. bedfordi is higher in the second half of the night. This was inconsistent with the result of the sticky trap collection described above. Although the reason for this is not clear at present, the most plausible explanation is that $S$. bedfordi may have two flight phases of different function. Probably, the flight after sunset is the dispersal flight by which the sandflies get out to outer open space and the flight after midnight might be some kind of searching flight.

The total number of sandflies captured by the two light traps on the night of 23 January was 215 , about five times larger than that on the night of 24 January (Tables 3 and 4). The reason remains unknown but this result might be due to meteorological factors such as wind direction and wind velocity, both of which will directly affect the flight of the sandflies, especially, flight distance.

The proportion of females in each trap collection was also investigated in the present study. Overall, it was extremely high (Tables 1, 3, 4 and 6). The proportion of females collected was more than $90 \%$ both in the sticky and light trap collections
(Tables 1, 3 and 4). It is suggested that such a highly female-biased sex ratio in these two different-type trap collections is due to site tenaciousness or weaker dispersal urge of males, as Yuval and Schlein (1986) have suggested for P. papatasi collected in the Jordan Valley. Among the seven sandfly species captured in Mukusu, most males might tend to remain at their emergence sites after emergence, where copulation might take place.

The proportion of females in the goat-baitedtrap collection was also high $(78.3 \%$; Table 6$)$. It is suggested that this depends on a habit which is particular to female sandflies, i.e., blood feeding. In the phlebotomine sandflies, only females feed on blood (Lane, 1987), and a female that wants to feed on an animal searches for it by flying. Furthermore, it is considered that the migration by flight is necessary for the female sandflies not only to have a blood meal but also to search for their oviposition sites. Therefore, the females may easily tend to be victims of any trap.

In the present study, three species of sandflies (P. martini, S. bedfordi and $S$. schwetzi) were captured with the goat-baited trap (Table 6). The temporal change in the number of sandflies captured with the goat-baited trap (see Fig. 2) showed that an intensive attraction of these three species of sandflies to the goats occurred around midnight. However, no actual blood feeding was observed. Mutinga et al. (1986b) studied the host preference of wild sandflies in Baringo District, Kenya by using the traps of six different animal baits. They observed that 11 species which included P. martini, S. bedfordi and S. schwetzi were captured with the goat-baited trap. The findings of the present study confirmed this. They also observed that $P$. martini actually fed on the goat and that $S$. bedfordi and $S$. schwetzi did not. However, actual feeding on the goats by $P$. martini females was not found in the present study. P. martini females may have been collected before they had the opportunity to feed on the goats. It is unknown whether $S$. bedfordi and $S$. schwetzi feed on goats in nature at present.

In the present study, for $P$. martini, not only females but also males were captured by the goatbaited trap (Table 6) although the males of the phlebotomine sandflies do not feed on blood (Lane, 1987). This suggests that males of this species are attracted to the goats for mating. 
The physiological condition of a total of 495 females captured with the three different types of traps was investigated in the present study. The results showed that almost all of the females captured were unfed and nulliparous (see Tables 2 and 5). This suggests that younger female sandflies show stronger nocturnal flight activity.

Through this field study, some important findings and suggestions on the biology of sandflies in Kenya were obtained. Further biological studies in the field are needed.

\section{ACKNOWLEDGEMENTS}

We thank Dr. K. Akai of Kenya Medical Research Institute (KEMRI), Nairobi, Kenya and Drs. S. Yagi and M. Mugunga of the International Centre of Insect Physiology and Ecology (ICIPE), Nairobi for their encouragement and useful advice. We are also grateful to Mr. J. P. Mwanyumba, Mr. R. Lugalia and Mr. S. Odongo of KEMRI, and Mr. D. M. Omogo of ICIPE for their skillful technical assistance. This study was financially supported by Japan Society for the Promotion of Science.

\section{REFERENCES}

Adler, S. and O. Theodor (1957) Transmission of disease agents by phlebotomine sand flies. Annu. Rev. Entomol. 2: 203-226.

Basimike, M., M. J. Mutinga and R. Kumar (1992a) Habitat preference and seasonal variations of phlebotomine sandflies (Diptera, Psychodidae) in Marigat Area, Baringo District, Kenya. Insect Sci. Applic. 13: 307-314.

Basimike, M., M. J. Mutinga, R. Kumar and D. Munyinyi (1992b) Relative abundance of adult phlebotomine sand flies (Diptera: Psychodidae) in relation to soil characteristics of their breeding sites in Baringo District, Kenya. Environ. Entomol. 21: 1114-1120.

el Said, S., J. C. Beier, B. M. el Sawaf, S. Doha and E. el Kordy (1986) Sand flies (Diptera: Psychodidae) associated with visceral leishmaniasis in El Agamy, Alexandria Governorate, Egypt II. Field behavior. J. Med. Entomol. 23: 609-615.

Heisch, R. B., C. A. W. Guggisberg and C. Teesdale (1956) Studies in leishmaniasis in East Africa. II. The sandflies of the Kitui kala-azar area in Kenya, with descriptions of six new species. Trans. R. Soc. Trop. Med. Hyg. 50: 209-226.

Lane, R. P. (1987) Phlebotomine sandflies. In Manson's Tropical Diseases. 19th ed. Appendix III (P. E. C. Manson-Bahr and D. R. Bell eds.). Baillière Tindall, London, pp. 1395-1404.

Lewis, D. J. (1971) Phlebotomid sandflies. Bull. WHO 44: 535-551.

Lewis, D. J. and D. M. Minter (1960) Internal structural changes in some African Phlebotominae. Ann. Trop. Med. Parasit. 54: 351-365.

Minter, D. M. (1963a) Studies on the vector of kala-azar in Kenya III. Distributional evidence. Ann. Trop. Med. Parasit. 57: 19-23.

Minter, D. M. (1963b) Three new sandflies (Diptera, Psychodidae) from East Africa, with notes on other species. Bull. Entomol. Res. 54: 483-495.

Minter, D. M. (1964) The distribution of sandflies (Diptera, Psychodidae) in Kenya. Bull. Entomol. Res. 55: 205217.

Muigai, R., J. I. Githure, G. S. Gachihi, J. B. O. Were, J. Leeuwenburg and P. V. Perkins (1987) Cutaneous leishmaniasis caused by Leishmania major in Baringo District, Kenya. Trans. R. Soc. Trop. Med. Hyg. 81: 600602.

Mutinga, M. J. (1985) Leishmaniasis in Kenya. Medicus 4: $11-22$.

Mutinga, M. J. and C. C. Kamau (1986) Investigations on the epidemiology of leishmaniasis in Kenya. II. The breeding sites of phlebotomine sandflies in Marigat, Baringo District, Kenya. Insect Sci. Applic. 7: 37-44.

Mutinga, M. J., C. C. Kamau and F. M. Kyai (1986a) Investigations on the epidemiology of leishmaniases in Kenya IV. Breeding habitat of Phlebotomus duboscqi (Diptera: Psychodidae), a vector of Leishmania major in Marigat, Baringo District, Kenya. Insect Sci. Applic. 7: 727-729.

Mutinga, M. J., F. M. Kyai, C. Kamau and D. M. Omogo (1986b) Epidemiology of leishmaniasis in Kenya III. Host preference studies using various types of animal baits at animal burrows in Marigat, Baringo District. Insect Sci. Applic. 7: 191-197.

Mutinga, M. J. and J. M. Ngoka (1978) Incrimination of the vector of visceral leishmaniasis in Kenya. E. Afr. Med. J. $55: 337-340$.

Perkins, P. V., J. I. Githure, Y. Mebrahtu, G. Kiilu, C. Anjili, P. M. Ngumbi, J. Nzovu, C. M. Oster, R. E. Whitmire, J. Leeuwenburg, L. D. Hendricks and D. K. Koech (1988) The isolation of Leishmania donovani from Phlebotomus martini collected in Baringo District, Kenya. Trans. $R$. Soc. Trop. Med. Hyg. 82: 695-700.

Sudia, W. D. and R. W. Chamberlain (1962) Battery-operated light trap, an improved model. Mosquito News 22: 126-129.

WHO (1984) The leishmaniases. Report of a World Health Organization Expert Committee. Technical Report Series 701. World Health Organization, Geneva. $141 \mathrm{pp}$.

Wijers, D. J. B. and D. M. Minter (1962) Studies on the vector of kala-azar in Kenya I. Entomological evidence. Ann. Trop. Med. Parasit. 56: 462-472.

Yuval, B. and Y. Schlein (1986) Leishmaniasis in the Jordan Valley III. Nocturnal activity of Phlebotomus papatasi (Diptera: Psychodidae) in relation to nutrition and ovarian development. J. Med. Entomol. 23: 411-415. 